\title{
Basic Research on Blended Teaching Mode in Colleges and Universities
}

\author{
Shui Jin \\ School of Fashion Communication of \\ Beijing Institute of Fashion Technology \\ Beijing, 100029, China
}

\author{
Yanran Shang \\ Basic Education Department of Beijing Foreign Trade \\ School \\ Beijing, 100012, China
}

\begin{abstract}
Modern information technologies, like the Internet, cloud computing and big data, have brought unprecedented changes in people's thinking, lifestyle and learning style, thus promoting educational reform and innovation. This work aimed to make good use of blended teaching mode, develop and improve the blended innovative teaching mode of "students' independent learning" through pre-class guidance, online self-learning, classroom key points explaining, in-depth discussion online and offline, process evaluation and other possible methods with the help of information and network technology. In order to construct and promote the current blended teaching mode, this work analyzed the key points of the blended teaching mode construction and the teaching and learning advantages in the blended teaching mode, which could be beneficial for readers.
\end{abstract}

Keywords-Blended teaching mode; Colleges and universities; Informatization; Teaching reform

\section{INTRODUCTION}

In 2002, American scholars Harvi Singh and Chris Reed made a comprehensive discussion on the content and form of the blended teaching model, and introduced it to China in 2003 [1]. The blended teaching mode is not only an integration of classroom teaching and online learning, but also an internal integration of face-to-face teaching and various online learning forms. The core of the teaching is to take the initiative, enthusiasm and innovation of students in learning. It has characteristics of practice, scene, process and fragmentation. Most of previous courses are mainly based on classroom teaching, and students are still passively accepted in their studies [1]. The Ten-year Development Plan for Education Informatization (2011-2020) proposed by the Ministry of Education in March 2012 put forward that students should be regarded as a core component of the competency system, and emphasized that it is necessary to continue popularizing and improving information technology education, so as to make efforts to cultivate students' learning ability in the information environment, cultivate students' good habits of using information technology to study, enhance students' ability to ask questions, analyze problems and solve problems in the network environment [2].

An ideal blended learning model combines multiple functions to enable learners to participate in multiple formal and informal learning activities. It is built in a completely learner centric environment, from information to content, from skill assessment to support tools, and from training to

Beijing Institute of Fashion Technology Promoting the Connotation Development of Colleges and Universities Quota Specialty - Blended Teaching Curriculum Construction Project (NHFZ20180109). collaborative environment, all around the learner.

\section{Key Steps That the Blended Teaching Model NeEdS TO ADDRESS}

Preparation: This initial preparation step is to help students understand basic skills and general framework, and improve their learning skills in order to help them move on to the next step successfully.

Pre-class elaboration: This step is designed to explain to students the learning objectives, key elements and key concepts of the course they are studying, as well as its value.

Process demonstration: This demonstration step focuses on procedures, principles, concepts and processes, which is designed to help students master the skills.

Learning skills: This step helps students experience new skills in a safe environment to enhance their understanding of the content they have learned and achieve long-lasting results.

Effect feedback: This assessment step provides students with feedback on the effects of applying new skills in a secure environment to help them apply the skills in their actual work.

Formal learning: This auxiliary step is usually the first step into the formal work environment. Students can choose key knowledge such as principles and concepts obtained in formal learning.

Synchronization assistance: The mentoring step provides behind-the-scenes support from experienced business people, mentors, and experts to enable students to integrate their experiences with others.

Mutual aid learning: This step allows students to solve problems together with other students in the group, which deepens students' understanding of skills.

\section{The CurRent Four Modes of Blended TEACHING:}

Blended Learning should avoid the problem that the blended strategies are too simple to achieve the desired results, and the blended methods are too complex to be effective. The reason for this phenomenon is that many education and training practitioners do not have a deep understanding of blended learning, so they cannot grasp the implementation points of blended learning. In particular, their understanding of blended learning still stays in a simple mix of simplified learning and 
traditional learning, therefore, it is difficult for them to develop an effective blended learning strategy. Blended Learning contains four application levels, which are described as follows:

The first level: an integration of online and offline. The combination of online and offline, that is, the blended mode of "E (e-Learning) + C (Classroom)". The concept of blended learning was first proposed as the combination of online and offline learning. When people realize that the single e-learning mode cannot achieve satisfactory results, they begin to consider the combination of e-learning and traditional classroom Learning, which achieves good results through practice. However, in a broad sense, blended learning also includes more content and levels.

The second level: an integration based on learning objectives. The blended learning based on learning objectives no longer only considers online and offline factors, but takes "achieving learning objectives" as the ultimate goal in the design of "blended" strategy, which has more extensive learning contents and methods. Goal-based blended learning may be traditional, and this level of blended learning is also called "integrated learning".

The third level: an integration of "teaching" and "learning". The integration of "teaching" and "learning" is the true meaning of blended learning. Applying the content of learning to practice through "study" is the purpose of learning in a higher level. Usually, "teaching" in equated with learning, but the actual situation completely misses "learning". Most of the face-to-face or online learning is just "teaching", which is not really learning. In fact, designing a mixture of "teaching" and "learning" is the most effective blended learning. This kind of blended learning is actually the easiest in design. At this level, there is still plenty of space for education and training personnel to achieve better results.

The fourth level: an integration of learning and work. Blended learning, which combines learning and work, is also called "embedded" learning or "action learning". It is not so much a learning method as a learning realm. In a sense, the work itself is learning. This level is more suitable for the corporate and training institutions and the graduation internship stage, which is usually reflected in some measures to promote employee work summary, experience sharing and business innovation.

\section{Positive Effects of THE Blended TeAching Model FOR TEACHING AND LEARNING}

The blended e-learning course design effectively integrates face-to-face classroom teaching with online teaching. It adopts the advantages of the two teaching methods and abandons their shortcomings, so that the two complement each other to improve students' learning outcomes. From the empirical research results, most students are satisfied with the design method of this kind of blended online teaching and give positive evaluation. This design not only satisfies learning characteristics and provides diversified and the latest teaching materials, but also captures learning records for teachers to use as a guide for students and the basis for textbooks revision. In addition, according to the learning obstacles encountered by students and the suggestions put forward, it is necessary to provide convenient network access conditions, improve students' information literacy, and arrange the proportion of face-to-face teaching content to online learning content based on teachers' teaching content and teaching conditions. It is the direction that must be improved in the future, so that teaching and learning activities benefit from the use of online media.

\section{A. Positive effects of the establishment of blended teaching system for the teacher teaching}

1) Giving full play to the guiding role of teachers

In this teaching mode, the role of teachers changes from the transmission of knowledge to the guide of learning, and their role of "mentor" becomes more apparent. Teachers can control the learning process of students as a whole, and their design and management of teaching resources are freer. Teachers can get rid of the limitations of the textbook outline when preparing relevant teaching resources, which means that they can not only upload micro-video with the characteristics of fragmentation, visualization, structure and nonlinearity, but also upload teaching courseware and study cases for students to learn. Teachers can update teaching resources in a timely manner, providing students with the latest and most popular learning resources in the subject area and keeping up with the development of the discipline.

\section{2) Keeping abreast of student's learning status}

One of the biggest characteristics of online teaching is that it can use the network to comprehensively and completely record students' learning behavior. In addition to understanding student's learning situation, it can also be used as a reference for evaluation. Almost all learning status is recorded, including the number of times the learner logs into the online teaching system, the number and time of the learner's browsing of each learning material, the learner's completion of each online assignment, and the learner's participation in the discussion forum, which are significantly related to the learner's final learning outcomes. These indicators are factors that affect the final learning outcomes of students, so instructors can use these indicators to understand each student's learning situation, and supervise students with poor performance in real-time to improve their learning outcomes [3].

\section{3) It is conducive to the management of shared teaching} resources

In the blended teaching process, the amount of teaching resources involved is relatively large, but teachers are required to do fine-grained, detailed, and step-by-step implementation. Teachers should have regular teaching schedules, syllabus, teaching courseware, teaching materials, teaching videos, key points and difficulties, and extracurricular teaching resources, which can be uploaded to the platform.

\section{4) Improving the construction of the teaching evaluation} system

Blended teaching is divided into online and offline evaluation system in the evaluation system, and the previous assessment methods are still used offline. The integral way can be used in online evaluation system construction to manage. The attendance management system on the platform automatically records students' attendance every time to form attendance scores. For students' preview management, 
homework management and online examination management, integral system is adopted to accumulate, and finally the traditional offline and online assessment system is formed

\section{B. Positive effects of the establishment of blended teaching system for students learning:}

1) Online learning makes the finishing point

As an important carrier of digital teaching, the microcourse is loved by teachers with its short and precise characteristics, which brings a new revolution in the teaching form and significantly improves teaching efficiency. The micro-course is an online learning method for students to selflearn and practice internalization outside the classroom or in the family based on the teaching objectives and teaching content. It emphasizes interactivity, strengthens the interaction between teachers and students, guides students to combine eyecatching, brain-moving and hands-on, and avoids teachers' single boring lecture. It has short time limits for 5-15 minutes, which pays attention to timeliness, and strives to be short, concise, simple and practical. Micro-teaching and text learning should be synchronized, acting as an important complement to text learning.

\section{2) Inspiring students' self-management skills}

The Soviet educator Suhomlinski once said: "Only the education that can stimulate students to carry out self-education is the real education." Self-management is the foundation of self-education, the driving force for the growth of students' life, and the important values that modern education pursuits. The learning characteristics of instant, open, autonomous, and generative determine that blended teaching should be guaranteed by students' self-management. This kind of selfmanagement involves not only knowledge learning, but also aspects of habit formation, thinking innovation, cooperation and communication, which is a high degree of integration of knowledge, love, intention and behavior.

3) Combination of classroom discussions and online discussion

Online interaction is divided into two types of interaction: synchronous and asynchronous. Due to the time limit, it is impossible to carry out in-depth discussions in class. Therefore, discussion space can be opened up in the "discussion" board of the online teaching platform to continue discussions. In this way, each student can deeply learn and be guaranteed the opportunity to speak.

\section{4) Flexible and convenient learning mode}

Teachers can upload the pre-class materials, classroom teaching videos, after-school exercises and test questions to the platform, in which students can preview and practice in their own cloud classroom terminal, which becomes very flexible and convenient in time and space. At the same time, when students do not understand in the classroom, they can re-enter the cloud classroom platform for further review.

\section{5) Feedback on learning status in a timely manner}

The platform will automatically record the learning process of students. For each learning module, teachers can easily find out through the platform whether students have completed it voluntarily or not, so that teachers can supervise students, and at the same time, the platform will also send a reminder signal. It is possible to promote learning for students who cannot manage themselves. Through online fragmented learning, students can reasonably layout their own learning time.

\section{SUMMARY}

The informatization teaching mode shifts from the original teacher-centered inculcation to the learner-centered inquiry. The teaching goal is changed from the original transfer of knowledge to the cultivation of students' creative thinking and the improvement of students. With the rapid development of computer technology and the maturity of Internet technology, more and more people are aware of the importance of blended learning. Blended learning is a mixture of traditional face-toface classroom teaching and online learning, a mixture of independent learning, collaborative learning, accepting learning and discovering learning, a mixture of real classroom environment and virtual network environment, and a mixture of online and offline communication between teachers and students. At present, blended teaching has become the mainstream of informatization teaching mode [2].

\section{REFERENCES}

[1] Shi Wei. Research on Blended Teaching Design and Practice Based on Micro-video[J]. Education and Teaching Forum, 2017, Issue 03.

[2] Wang Que, Yang Zhuo. Design of Blended Teaching Mode Based on Cloud Classroom[J]. China Educational Technology, 2017, Issue 04.

[3] Hu Huahai, Ye Jianhua. Research on the Blended Teaching Model of "OTO" on the Cloud Classroom Platform[J]. Peak Data Science, 2017, Issue 08. 